\title{
Flood risk governance arrangements in Europe
}

\author{
P. Matczak ${ }^{1,2}$, J. Lewandowski ${ }^{1}$, A. Choryński ${ }^{1}$, M. Szwed ${ }^{1}$, and Z. W. Kundzewicz ${ }^{1,3}$ \\ ${ }^{1}$ Institute for Agricultural and Forest Environment, Polish Academy of Sciences, Bukowska 19, \\ 60-809 Poznań, Poland \\ ${ }^{2}$ Institute of Sociology, Adam Mickiewicz University, Szamarzewskiego 89c, 60-568 Poznań, Poland \\ ${ }^{3}$ Potsdam Institute for Climate Impact Research, Telegrafenberg 31, 14473 Potsdam, Germany
}

Correspondence to: P. Matczak (matczak@amu.edu.pl)

Received: 15 April 2015 - Accepted: 15 April 2015 - Published: 11 June 2015

\begin{abstract}
The STAR-FLOOD (Strengthening and Redesigning European Flood Risk Practices Towards Appropriate and Resilient Flood Risk Governance Arrangements) project, funded by the European Commission, investigates strategies for dealing with flood risk in six European countries: Belgium, the UK, France, the Netherlands, Poland and Sweden and in 18 vulnerable urban regions in these countries. The project aims to describe, analyse, explain, and evaluate the main similarities and differences between the selected EU Member States in terms of development and performance of flood risk governance arrangements. It also discusses the scientific and societal importance of these similarities and differences.

Attention is paid to identification and characterization of shifts in flood risk governance arrangements and in flood risk management strategies and to determination of triggering factors and restraining factors.

An assessment of a change of resilience and appropriateness (legitimacy, effectiveness, efficiency) of flood risk governance arrangements in Poland is presented and comparison with other European countries is offered.
\end{abstract}

\section{Flood risk is serious and losses are growing}

Floods are one of the most serious natural risks in Europe. Severity and magnitude of floods in the continent in 19852009 have increased (Kundzewicz et al., 2013; Barredo, 2007), due to changes in non-climatic and climatic factors. The human factors: population growth in flood-prone areas, urbanization, and economic development contribute to the growing scale of material losses (Rojas et al., 2013). The losses in economic terms and in terms of human lives are still high, despite the efforts to protect against floods. In some years, the annual flood damages in Europe extend over EUR 10 billion and several dozens of casualties.

\section{Flood risk management strategies}

There is a growing concern about inefficiency of the existing approaches to coping with floods since losses are not decreasing, despite the efforts. Moreover, the environmental concerns have been come to the forefront in the context of selection of methods of dealing with food risks. New ideas and approaches have emerged in some countries (e.g., the Netherlands, Germany, the UK), such as "making room for the river", or - compartmentalization (selection of areas to be inundated in case of deluge). New ideas change the "philosophy" of the flood safety. Resilience instead of resistance is highlighted (Warner et al., 2013) and more emphasis is put on the environmental limits and search for balance between man and nature (Verkerk and Buuren, 2013). As a result, the structural defence methods are criticized and the non-structural methods discussed instead (Dawson et al., 2011).

This transformation is a newly emerging issue and in order to analyse the changes in the flood risk management, disaggregation of the problem into detailed categories is needed. Flood Risk Management Strategies (FRMSs) can be defined as approaches for dealing with flood risks, distinguisheable from one another by their focus on the probability of flooding, its consequences or on recovery after a flood has struck (Hegger et al., 2014). Five FRMS can be distinguished: (i) prevention, (ii) defence, (iii) mitigation, (iv) preparation, and (v) recovery (Fig. 1). 


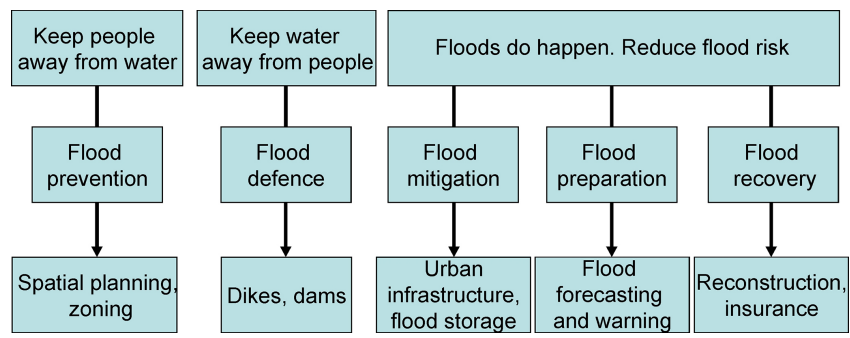

Figure 1. Flood Risk Management Strategies and exemplary measures.

i. Within the flood prevention strategy, pro-active spatial planning is the main measure. It is assumed that floodrelated risks can be prevented by planning and land use policies (zoning) in order to keep people away from water and moving out of harm's way. Particularly housing developments are to be located at a safe distance from the hazard and at adequate elevation. Thus, spatial planning is a tool for reducing flood vulnerability (Fleischauer, 2008). Preparation of flood risk and flood damage maps, in accordance with the Floods Directive (FD) of the European Union are relevant examples. At the same time, evaluation of resilient land use planning needs to consider different interests, places, scales and times as the endogenous features of the local context (Lloyd, 2011) along with solving "wicked problems" with planning (Hartmann, 2012).

ii. The flood defence strategy is the dominant one, focused on decreasing the probability of flooding. Various types of infrastructural measures are used for this purpose: such as dikes, dams, embankments, sluices, relief channels, etc. Flood defences were, historically, the most popular approach attracting high investment in infrastructure.

Flood prevention and flood defence follow a fail-safe (safe from failure) stance, i.e. planning for a resistant system that cannot fail. Flood mitigation, preparation, and recovery follow a safe-fail stance - resilient systems can fail but they should fail in a safe way.

iii. The flood mitigation strategy focuses on decreasing the consequences of flooding. Retention of water is the most prominent measure, in this respect. Within this strategy floods are treated as unavoidable and preparing the land and buildings to retain water and to be resistant to the excess of water is the principal idea.

iv. Within the flood preparation strategy emergency systems are kept: warning structures, evacuation plans, crisis management structures etc.

v. The flood recovery strategy deals with the consequences of the floods: help to victims, reconstruction, business

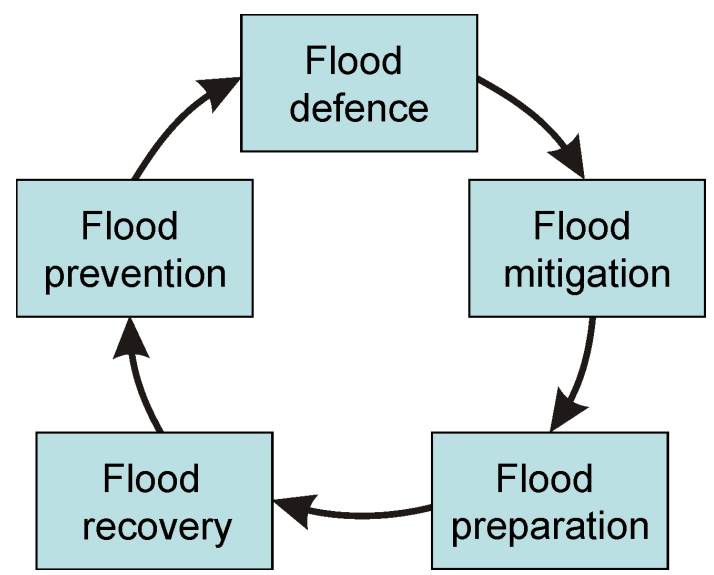

Figure 2. Flood Risk Management Strategies can be regarded as the phases of the emergency management cycle.

continuity. Insurance systems are increasingly important in financing the reconstruction or rebuilding. It is a matter of analysis to indicate which institutional or legal design concerning insurance systems is the most feasible solutions would be the most efficient.

\section{Shift and diversification of strategies}

In reality, all types of strategies are usually applied as a sitespecific mix. However, their weights differ due to many factors. In the Fig. 1 the strategies are presented as a set of approaches, however, our interest is in the dynamic aspect: how the emphasis on particular strategies change. In terms of the strategies presented above, the general shift can be identified of the weakening the structural flood defence strategy and strengthening non-structural measures, in various proportions.

The strategies presented in Fig. 2 loosely resemble the phases of the emergency management cycle. They are connected, but can be distinguished as they differ in terms of measures applied.

Aerts et al. (2008) argue that in order to optimize flood safety, one needs to avoid relying on one strategy. Instead, a diversification of strategies is being considered, i.e. a portfolio of them should be designed and applied, making the system less vulnerable to a variety of hazard events, under strong uncertainty.

It can be argued that the traditional strategy of flood risk management has been based on structural defences (defence strategy). The engineered constructions: dykes, embankments, dams and other defence structures have been built in order to constrain water and prevent it to flow outside the designated area. Emerging ideas in flood management involve less emphasis on the defence strategy and more - on other ones. However, such a change is problematic. The shift can be hampered by strongly rooted institutional cul- 
tures tending to rely on engineered approaches (Harries and Penning-Rowsell, 2011).

How strategies are implemented and operate in a particular context depends on Flood Risk Governance Arrangements (FRGA) - the actors, discourses, rules and resources through which Flood Risk Management Strategies are developed and put into practice (Wiering and Arts, 2006). The strategies are embedded within an institutional, social, legal, economic, and scientific context.

Changes in a given mix of flood risk governance strategies involve changes of Flood Risk Governance Arrangements, in terms of changing roles of actors and power, changes of rules, discourses and resources allocation. Also, the changes of the Flood Risk Governance Arrangements involve changes in the order of relevant importance of strategies. The EU Floods Directive of 2007 is an interesting case as it may involve some changes in strategies (it stresses the importance of improvement and balance of strategies) and it may change the existing Flood Risk Governance Arrangements.

\section{New measures - ideas are discussed, but are they implemented, are they feasible?}

The role of flood risk mitigation measures in overcoming gaps in flood risk management dominated by traditional infrastructural solutions is widely discussed in the Western European countries (Nquot and Kulatnunga, 2014). Studies indicate (Osberghaus, 2015) that the interest in flood mitigation measures increases in places experienced with floods. Nevertheless, even in the Western European countries, the mitigation strategy is not commonly used. Moreover, it is avoided by decision makers, because it is the solution that may require actions uncomfortable for the authorities (Brody and Highfield, 2013). At the same time, in literature, one can find numerous examples of flood mitigation measures together with broad analysis of their efficiency (i.e. green roofs, permeable parking lots, see: Lee et al., 2013).

In case of Poland, the defence strategy clearly dominates, but there are attempts to test other. The mitigation strategy is implemented mostly at the level of pilot studies. The problem of urban flash floods has been discussed by the municipal authorities. At this point some municipalities have decided to introduce a rainwater-conveyance tax, based on the area of impervious surfaces. This relates to roofs and large parking lots. This solution of legislative nature was meant to give an incentive for private actors to invest in rainwater retention systems. However, the flood mitigation effect has not been reached because of the way of implementing the taxation. The level of charges was too low to become an impulse for a change. Another flood risk mitigation measure that is implemented in Poland on a larger scale is the small retention programme (in the lowlands as well as in the mountain area) led by the State Forests - National Forest Holding. However, this activity, although widely introduced, has a minor flood miti- gation impact. Due to its location, away from large rivers, it has more of an environmental influence (needed by the State Forests for improvement of cultivation) than flood mitigation effect. The implemented measures are not perceived by the water/flood management sector as effective in reducing flood risk. In their case, flood risk mitigation effect is rather thought as a side effect of undertaken actions.

\section{Information on the STAR-FLOOD project}

The STAR-FLOOD (Strengthening and Redesigning European Flood Risk Practices Towards Appropriate and Resilient Flood Risk Governance Arrangements) project of the 7th Framework Programme of the European Union, investigates strategies for dealing with flood risk in six European countries: Belgium, France, the Netherlands, Poland, Sweden, and the UK, and in 18 vulnerable urban regions in these countries. The project assesses the institutional embedding of these strategies from a combined public administration and legal perspective, with the aim to make European regions more resilient to flood risks. The project aims to describe, analyse, explain, and evaluate the main similarities and differences between the six countries represented in the consortium of the STAR-FLOOD project in terms of development and performance of flood risk governance arrangements. It also discusses the scientific and societal importance of these similarities and differences. Adaptation capacity in consortium countries of the STAR-FLOOD project is high, compared to other regions.

Attention is paid to identification and characterization of shifts in flood risk management strategies and in flood risk governance arrangements and to determination of triggering factors and restraining factors.

An assessment of a change of resilience and appropriateness (legitimacy, effectiveness, efficiency) of flood risk governance arrangements are presented and compared between the six countries. Eventually, appropriate and resilient Flood Risk Governance Arrangements (FRGAs) for dealing with flood risks in vulnerable urban regions are searched.

\section{Results}

The countries participating in the FLOOD-STAR project represent various types of flood risks. More than a half of the Netherlands' territory is flood prone. The level of protection is high, but a damage of eventual inundations would be very high. In Sweden, the flood risk is relatively small. In Poland, mostly fluvial and pluvial floods occur while in Sweden flood risk can be also related to dams (e.g. spillways). In Sweden and Poland, low temperature effects are important, that may lead to snowmelt and/or ice-jam flooding. In the Netherlands, France, Belgium and England, also tidal foods and storm surge pose a danger. Coastal storm surges have hit Polish Baltic Sea coast as well. 
Large destructive floods have occurred in Poland, the UK and France. In Poland, many towns, including large cities, are located on the Vistula, the Odra, and their tributaries. Flood risk and flood preparedness became matters of broad concern, following the dramatic inundations in Poland in 1997 and 2010, in which the number of fatalities exceeded 55 and 20, respectively; national flood losses were estimated to reach the level of billions of Euros (reaching, or exceeding, $1 \%$ of the Polish GDP and the topic made it to cover stories).

The countries vary in terms of the legal and administrative framework. Belgium is a federal state while other countries are unitary and centralized in terms of flood and water related issues. The Dutch administrative structure culture is traditionally consensus-based, while conflicts are more visible in Poland. In England, the centralization is very high and local governments weak. Contrary, in Sweden, local governments are very strong and have a dominant position regarding landuse and planning and the implementation of national policies on local level.

In Poland, a vigorous public dispute on flood risk and flood preparedness has taken place, particularly during, and following, the disastrous flood in July 1997 and May-June 2010. Testing public opinion in polls demonstrated that in 1997 the nation was critical to the central government and this criticism may have contributed to the defeat of the ruling coalition (Kundzewicz, 2014).

The general legal framework differs between the UK, with a Common Law system and the rest of the countries with coded based laws. In terms of the stability, in Poland the legal and administrative system underwent significant changes (the last fundamental change was in 1990, after the fall of the communist regime and the transformation into the market economy and democratic regime), while in the other countries the legal and administrative systems change evolutionally. Further important factors triggering change in Poland were: the occurrence of a dramatic flood in July 1997 and the country's entry into the European Union in May 2004.

The influence of the EU is significant but also uneven. In the Netherlands, a sober approach to the implementation of the Flood Directive can be found, while in Poland it gives a momentum for more profound changes of the flood risk management.

In terms of diversification of the Flood Risk Management Strategies in analysed countries, limited substantiation of the diversity of strategies can be observed. The flood protection measures have traditionally been are mostly structural and include embankments and storage reservoirs. In the Netherlands, the idea of the room for the rivers is occasionally implemented. Also in Belgium, England, France, and Poland the flood mitigation type projects are implemented. They are however, rather pilot projects then the more general strategies shift. Within the discourses the shift is more pronounced. The emergence of environmental concerns and increasing emphasis of the win-win (co-benefit) measures by linking nature conservation with flood management can be found in all the project countries.

Acknowledgements. The preparation of this paper was funded from the STAR-FLOOD Project (STrengthening And Redesigning European FLOOD risk practices: Towards appropriate and resilient flood risk governance arrangements) under the European Union's Seventh Programme for Research, Technological Development and Demonstration. This research has received funding from the European Commission under grant agreement no. 308364.

\section{References}

Aerts, J. C. J. H., Botzen, W., Van der Veen, A., Krywkow, J., and Werners, S.: Dealing with uncertainty in flood management through diversification, Ecol. Soc., 13, 41-57, 2008.

Barredo, J. I.: Major flood disasters in Europe: 1950-2005, Nat. Hazards, 42, 125-148, 2007.

Brody, S. D. and Highfield, W. E.: Open space protection and flood mitigation: A national study, Land Use Policy, 32, 89-95, 2013.

Dawson, R. J., Ball, T., Werritty, J., Werritty, A., Hall, J. W., and Roche, N.: Assessing the effectiveness of non-structural flood management measures in the Thames Estuary under conditions of socio-economic and environmental change, Global Environ. Chang., 21, 628-646, 2011.

Fleischauer, M.: The role of spatial planning in strenghtening urban resilience, in: Resilience of cities to terrorist and other threats, edited by: Pasman, H. J. and Kirilov, I. A., Learning from 9/11 and further research issues, Dordrecht: Springer, 273-298, 2008.

Harries, T. and Penning-Rowsell, E.: Victim pressure, institutional inertia and climate change adaptation: The case of flood risk, Global Environ. Chang., 21, 188-197, 2011.

Hartmann, T.: Wicked problems and clumsy solutions: Planning as expecation management, Planning Theory, 11, 242-256, 2012.

Hegger, D. L., Driessen, P. P., Dieperink, C., Wiering, M., Raadgever, G. T., and van Rijswick, H. F.: Assessing Stability and Dynamics in Flood Risk Governance, Water Resour. Manag., 28, 4127-4142, 2014.

Kundzewicz, Z. W.: Adapting flood preparedness tools to changing flood risk conditions: the situation in Poland, Oceanologia, 56, 385-407, 2014.

Kundzewicz, Z. W., Pińskwar, I., and Brakenridge, G. R.: Large floods in Europe, 1985-2009. Hydrolog. Sci. J., 58, 736-736, 2013.

Lee, J. Y., Moon, H. J., Kim, T. I., Kim, H. W., and Han, M. Y.: Quantitative analysis on the urban flood mitigation effect by the extensive green roof system, Environ. Pollut., 181, 257-261, 2013.

Lloyd, M. G.: The spatial planning model: balancing private sector interests with the "common good", Borderlands: The Journal of Spatial Planning in Ireland, 1, 9-23, 2011.

Nquot, I. and Kulatnunga, U.: Flood Mitigation Measures in the United Kingdom, Procedia Economics and Finance, 18, 81-87, 2014.

Osberghaus, D.: The determinants of private flood mitigation measures in Germany - Evidence from a nationwide survey, Ecol. Econ., 110, 36-50, 2015. 
Rojas, R., Feyen, L., and Watkiss, P.: Climate change and river floods in the European Union: Socio-economic consequences and the costs and benefits of adaptation, Global Environ. Chang., 23, 1737-1751, 2013.

Verkerk, J. and van Buuren, A.: Space for the river, a condensed state of the art, in: Making space for the river: governance experiences with multifunctional river flood management in the US and Europe, edited by: Warner, J. F., van Buuren, A., and Edelenbos, J., IWA Publishing, 2013.
Warner, J. F., Edelenbos, J., and van Buuren, A. (Eds.): Making space for river: governance challenges, in: Making space for the river: governance experiences with multifunctional river flood management in the US and Europe, IWA Publishing, 2013.

Wiering, M. and Arts, B.: Discursive shifts in Dutch water management: "Deep" institutional change or adaptation strategy?, Нydrobiologia, 565, 327-338, 2006. 